\title{
The influence of old oil pollution on the composition of organic matter and the microbiological activity of peat soils in the permafrost zone
}

Solovyova A.A., Rozanova M.S.

Lomonosov Moscow State University, Moscow, Russia, solovyova.a.a@mail.ru

doi: 10.36291/HIT.2019.solovyova.078

Cryolithozone biogeocenosis are characterized by low biological turnover capacity, mosaic of soil and vegetation cover, poor species composition of phytocenoses and their low bioproductivity.

Samples of clean and oil-contaminated oligotrophic peat of undisturbed structure (monoliths) were taken on hilly peatlands of the northern taiga of Western Siberia, developing in permafrost conditions. Peat was maintained throughout the experiment at natural humidity, for which the monoliths were regularly weighed (once every three days) and, if necessary, sprayed with water. The thawing periods (temperature $+7^{\circ} \mathrm{C}$ ) and freezing $\left(-10^{\circ} \mathrm{C}\right)$ lasted 14 days, the duration of the experiment was 4 months.

To assess the effect of pollution on the composition of organic matter and the change in the microbial community, the following parameters were determined: the content and composition of labile humic substances (Clhs) (labile humic (Clha) and fulvic acids (Clfa), total carbon content (Ctot), water-extractable carbon content (Cw), basal respiration (BR), microbial biomass carbon (MB), petroleum content in samples (OilP). Results are shown in Table 1.

Table 1. The content of oil products, various fractions of organic matter and indicators of microbiological activity of peat

\begin{tabular}{|c|c|c|c|c|c|c|c|c|c|c|c|c|c|}
\hline & $\begin{array}{c}\text { Depth, } \\
\text { cm }\end{array}$ & $\begin{array}{c}\text { Clhs, } \\
\%\end{array}$ & $\begin{array}{c}\text { Clha, } \\
\%\end{array}$ & $\begin{array}{c}\text { Clfa, } \\
\%\end{array}$ & $\begin{array}{l}\text { Cha/ } \\
\text { Cfa }\end{array}$ & $\begin{array}{c}\text { Cw, } \\
\%\end{array}$ & $\begin{array}{c}\text { Ctot, } \\
\%\end{array}$ & $\begin{array}{c}\text { Cw/ } \\
\text { Ctot, \% }\end{array}$ & $\begin{array}{c}\text { Cw/ } \\
\text { Clhs,\% }\end{array}$ & $\begin{array}{l}\text { Clhs/ } \\
\text { Ctot, \% }\end{array}$ & $\begin{array}{c}\mathrm{BR}, \\
\mu \mathrm{gC} \mathrm{C}- \\
\mathrm{CO}_{2} / \mathrm{g} \times \mathrm{h}\end{array}$ & $\begin{array}{c}\mathrm{MB}, \\
\mu \mathrm{gC} g\end{array}$ & $\begin{array}{l}\text { OilP, } \\
\text { mg kg }\end{array}$ \\
\hline Oil & 0 & 12.18 & 3.42 & 8.77 & 0.39 & 1.46 & 42.57 & 3.44 & 12.02 & 28.62 & 12.90 & 1088.6 & 2247 \\
\hline Oil & 15 & 18.02 & 7.08 & 10.94 & 0.74 & 1.29 & 44.38 & 2.90 & 7.13 & 40.61 & 23.76 & 1821.6 & 9581 \\
\hline Oil & 20 & 18.00 & 6.58 & 11.42 & 0.58 & 0.96 & 50.45 & 1.91 & 5.36 & 35.68 & 17.57 & 1528.6 & 13300 \\
\hline Oil & 25 & 21.56 & 7.58 & 13.98 & 0.54 & 0.80 & 50.32 & 1.58 & 3.69 & 42.84 & 6.60 & 503.1 & 25707 \\
\hline Oil & 30 & 20.83 & 6.75 & 14.08 & 0.48 & 0.57 & 53.08 & 1.07 & 2.73 & 39.24 & 4.63 & 197.6 & 35240 \\
\hline Clear & 0 & 15.45 & 2.90 & 12.54 & 0.26 & 1.67 & 43.09 & 3.88 & 10.83 & 35.84 & 109.69 & 8876.8 & 1161 \\
\hline Clear & 15 & 21.70 & 6.76 & 14.94 & 0.45 & 1.12 & 44.85 & 2.50 & 5.17 & 48.38 & 69.21 & 5475.2 & 5064 \\
\hline Clear & 23 & 21.69 & 7.19 & 14.49 & 0.50 & 0.89 & 50.73 & 1.76 & 4.12 & 42.75 & 11.52 & 1357.4 & 5940 \\
\hline Clear & 30 & 17.42 & 6.22 & 11.20 & 0.54 & 0.65 & 51.79 & 1.25 & 3.71 & 33.64 & 5.43 & 260.3 & 6162 \\
\hline Clear & 40 & 20.51 & 6.71 & 13.80 & 0.50 & 0.63 & 51.22 & 1.23 & 3.07 & 40.04 & 4.42 & 213.4 & 5785 \\
\hline
\end{tabular}

The content of the Clhs Clear variant is relatively evenly distributed over the profile, decreasing in its lower part. In the Oil variant, an increase in the content of Clhs occurs at the bottom of the profile; this is probably due to the increased hydrophobicity of peat due to the content of Oil, and soluble fractions of organic substances accumulate in the lower part of the profile contaminated with oil products. Low biological activity in the upper horizons contributes to this, since bioavailable organic matter is not consumed by microorganisms.

Differences in the indicators of microbiological activity between the Clear and Oil variants are maximal in the surface layers of peat. In the upper layer of the BR in the Clear variant, it is almost 8 times higher than in the same peat layer in the Oil variant, the carbon content of the microbial biomass was $8900 \mu \mathrm{gC} / \mathrm{g}$ in the Clear variant and $1090 \mu \mathrm{g} / \mathrm{g}$ in the Oil variant. 